\title{
VACCINE STORAGE IN SOUTH WEST NEW SOUTH WALES
}

Glenda Fisher, Environmental Health Officer

Tony Kolbe, Director,

South West Centre for Public Health

$\mathbf{T}_{\mathrm{p}}^{\mathrm{o}}$ 0 ensure the potency of vaccines used in immunisation programs it is essential that vaccine temperatures be maintained between $2^{\circ} \mathrm{C}$ and $8^{\circ} \mathrm{C}$ during both storage and transport ${ }^{1}$ - the so-called vaccine "cold chain". Any deviation from this temperature range will result in some degradation of the vaccine. Exposure to temperatures outside the recommended range has a cumulative effect in reducing vaccine potency and cannot be reversed ${ }^{1}$.

This article reports on a survey of vaccine storage conditions in premises of five types of vaccine providers: local councils, hospitals, community health centres (CHCs), general practitioners (GPs) and pharmacies. The effectiveness of the distributing hospital pharmacy refrigerator was also assessed.

Because the South West Health District covers vast distances and experiences extremes of temperature, it is important to identify weaknesses in the cold chain as well as improve the standards of vaccine handling.

\section{MethodS}

A telephone survey of councils, hospitals and CHCs was conducted to identify premises at which vaccines were stored. A 10 per cent random sample of GPs and pharmacies was undertaken and included in the storage survey. Eighty premises were selected as a representative sample of the target population. The sample comprised 13 councils, 27 hospitals, $18 \mathrm{CHCs}, 12$ GPs and 10 pharmacies.

A letter was sent to a staff member (identified during the survey) at each location explaining the survey. At the initial visit to each premises a maximum/minimum thermometer was installed. The thermometer was placed in the vicinity of the vaccines in an upright position. Basic procedures on how to read the thermometer were explained to the staff member. The thermometer was read for a one-month period at approximately the same time every day, and the maximum and minimum temperatures were recorded on the temperature sheet provided. At the end of the survey period the temperature data sheet was returned to the South West Centre for Public Health. The thermometer was retained by the vaccine provider.

Each vaccine storage refrigerator was inspected to determine location of vaccines, other items stored such as food or beverages, excessive ice build-up, whether the refrigerator was regularly monitored, and whether there was an uninterruptable power supply to the refrigerator.

\section{RESULTS}

Compliance with the storage requirements was generally good (Table 3). Of the 80 premises, 67 had vaccines stored in the correct location. A total of 47 premises contained some form of temperature monitoring. Very few had a maximum/minimum thermometer. Only one of the premises studied read and recorded the temperature daily.

A total of 24 premises stored food and beverages in the vaccine refrigerator and 11 premises showed a build-up of ice.

Power interruptions were common due to blackouts or accidental disconnection of vaccine refrigerators in those service providers surveyed.

Compliance with the recommended temperature range was poor, with all five service providers reporting inappropriate temperatures for vaccines (Table 4). Wide variations occurred outside the recommended temperature range, with the highest temperature being $27^{\circ} \mathrm{C}$ and the lowest $-10^{\circ} \mathrm{C}$. Each group surveyed had vaccines exposed to sub-zero temperatures. With the exception of the pharmacy group, all groups had vaccines exposed to temperatures greater than $20^{\circ} \mathrm{C}$

\begin{tabular}{|c|c|c|c|c|}
\hline $\begin{array}{l}\text { Service } \\
\text { provider (n) }\end{array}$ & $\begin{array}{l}\text { Maximum } \\
\text { range }\end{array}$ & (median) & $\begin{array}{l}\text { Minimum } \\
\text { range }\end{array}$ & median) \\
\hline Council (13) & $0^{\circ} \mathrm{C}$ to $22^{\circ} \mathrm{C}$ & $\left(5^{\circ} \mathrm{C}\right)$ & $-4^{\circ} \mathrm{C}$ to $8^{\circ} \mathrm{C}$ & $\left(1^{\circ} \mathrm{C}\right)$ \\
\hline $\mathrm{CHC}(18)$ & $0^{\circ} \mathrm{C}$ to $22^{\circ} \mathrm{C}$ & $\left(5^{\circ} \mathrm{C}\right)$ & $-5^{\circ} \mathrm{C}$ to $14^{\circ} \mathrm{C}$ & $\left(2^{\circ} \mathrm{C}\right)$ \\
\hline Hospital (27) & $-3^{\circ} \mathrm{C}$ to $27^{\circ} \mathrm{C}$ & $\left(6^{\circ} \mathrm{C}\right)$ & $-10^{\circ} \mathrm{C}$ to $15^{\circ} \mathrm{C}$ & $\left(2^{\circ} \mathrm{C}\right)$ \\
\hline $\mathrm{GP}(12)$ & $1^{\circ} \mathrm{C}$ to $25^{\circ} \mathrm{C}$ & $\left(6^{\circ} \mathrm{C}\right)$ & $-6^{\circ} \mathrm{C}$ to $11^{\circ} \mathrm{C}$ & $\left(1^{\circ} \mathrm{C}\right)$ \\
\hline Pharmacy (10) & $0^{\circ} \mathrm{C}$ to $8^{\circ} \mathrm{C}$ & $\left(4^{\circ} \mathrm{C}\right)$ & $-2^{\circ} \mathrm{C}$ to $7^{\circ} \mathrm{C}$ & $\left(1^{\circ} \mathrm{C}\right)$ \\
\hline
\end{tabular}

\begin{tabular}{|c|c|c|c|c|c|c|c|}
\hline $\begin{array}{l}\text { Service } \\
\text { Provider } \\
\text { (n) }\end{array}$ & $\begin{array}{r}\text { Correct } \\
\text { location } \\
(\%)\end{array}$ & $\begin{array}{r}\text { Power } \\
\text { interruptions } \\
(\%)\end{array}$ & $\begin{array}{r}\text { Build-up } \\
\text { of ice } \\
(\%)\end{array}$ & $\begin{array}{l}\text { Store } \\
\text { food } \\
(\%)\end{array}$ & $\begin{array}{l}\text { Other } \\
\text { drugs } \\
(\%)\end{array}$ & $\begin{array}{r}\text { Other } \\
\text { appliances } \\
(\%)\end{array}$ & $\begin{array}{r}\text { Refrigerator } \\
\text { monitored } \\
(\%)\end{array}$ \\
\hline Council (13) & 11 (85) & $6(46)$ & $2(15)$ & $5(38)$ & $0(0)$ & $1(8)$ & $7(54)$ \\
\hline CHC (18) & $18(100)$ & $4(22)$ & 3 (17) & 7 (39) & $9(50)$ & 1 (6) & 7 (39) \\
\hline Hospital (27) & $20(74)$ & $15(55)$ & $2(8)$ & 1 (4) & $23(85)$ & 1 (4) & $18(67)$ \\
\hline GP (12) & 10 (83) & $3(25)$ & $3(25)$ & $4(33)$ & $9(75)$ & $2(17)$ & 7 (58) \\
\hline Pharmacy (10) & $8(80)$ & $4(40)$ & $1(10)$ & $7(70)$ & $9(90)$ & $5(50)$ & $8(80)$ \\
\hline Total $(80)$ & 67 (84) & $32(40)$ & 11 (14) & $24(30)$ & $50(62)$ & $10(12)$ & $47(59)$ \\
\hline
\end{tabular}

Note: Correct location - vaccines being stored in the main body of the refrigerator (not in the door).

Power interruptions - blackouts, accidental disconnection.

Build-up of ice - excessive ice in freezer compartment.

Store food and other drugs - storing food, beverages or pharmaceutical drugs in with the vaccines.

Other appliances - other electrical appliances were connected to the same power point.

Refrigerator monitored - whether refrigerator contained a thermometer. 


\section{Vaccine storage in South West NSW}

Continued from page 87

\section{DISCUSSION}

To store vaccines effectively, they must be located in the main body of the refrigerator with the temperature maintained between $2^{\circ} \mathrm{C}$ and $8^{\circ} \mathrm{C}$.

Storage location practices in the premises surveyed were generally acceptable, with most vaccines in the main body of the refrigerator. However, some refrigerators were overstocked and vaccines were stored in the door. Previous studies have indicated that the temperature in the door of the refrigerator is higher than the main body ${ }^{1}$. It is suggested that vaccine handlers should order only the amount of vaccine they will need rather than order in bulk. This will reduce the amount of storage time and ensure vaccines are used well before their expiry date.

Only one provider (a GP) maintained a refrigerator within the recommended temperature range. At this GP's surgery a staff member responsible for the vaccines maintained a $\log$ book and recorded the temperature of the refrigerator twice daily. It is essential that vaccine handlers record the temperature at least once daily in a log book and ensure the refrigerator is maintained appropriately.

It was observed that no refrigerator contained bottles of water, as recommended, to insulate the refrigerator ${ }^{1}$. The temperature fluctuation of most refrigerators may have been reduced if bottles of water had been stored in them.

Most vaccines are affected by freezing ${ }^{2}$. Hepatitis $B$ vaccine has a freezing point of $-0.5^{\circ} \mathrm{C}$ and the vaccine is destroyed if frozen ${ }^{3}$. The freezing point for absorbed diphtheria-tetanuspertussis (DTP) vaccine is between $-5^{\circ} \mathrm{C}$ and $-10^{\circ} \mathrm{C}^{3}$. It is alarming that many of the sites had temperatures low enough to destroy the potency of hepatitis B vaccine. Some premises also had temperatures which could affect the potency of DTP and tetanus toxoids.

The maximum/minimum thermometer is a good indicator of the temperature range to which vaccines are exposed, but gives no indication of the length of time the vaccine is at a particular temperature. It is important, therefore, to have a cold chain monitor in the refrigerator to measure the cumulative effect of temperatures on vaccines.

\section{CONCLUSION}

Our results suggest that vaccine handlers have insufficient knowledge about correct storage procedures and the risks associated with temperature extremes.

Despite published recommendations, vaccine handlers frequently fail to maintain the temperature within the recommended range. The mere placement of a vaccine product in a refrigerator without adequate monitoring is insufficient. Adequate training on correct storage locations and practices is essential for all staff handling vaccines.

Vaccine handlers should be encouraged to follow the National Health and Medical Research Council (NHMRC) guidelines ${ }^{2}$, with particular reference to the following:

- a maximum/minimum thermometer be placed in every vaccine refrigerator and the temperature recorded daily;

- a trained staff member at each location be responsible for maintaining the vaccine cold chain; and

- adequate training be given to all staff handling vaccines.

1. Carey MG. A review of childhood immunisation in New South Wales NSW Health Department, 1991.

2. NHMRC. Keep it cool: The vaccine cold chain guidelines for immunisation providers on maintaining the cold chain. Australian Government Publishing Service, Canberra, 1994.

3. Galazka A. Stability of vaccines. World Health Organisation, Geneva, 1989

\section{ACKNOWLEDGMENTS}

The co-operation of councils, hospitals, community health centres, general practitioners and pharmacists is gratefully acknowledged. The support from Public Health Unit staff is greatly appreciated.

The authors would also like to acknowledge Neil Stubbs for his involvement in the survey.

\section{PUBLIC HEALTH EDITORIAL STAFF}

The editor of the NSW Public Health Bulletin is Dr Michael Frommer, Director, Centre for Research and Development, NSW Health Department. Dr Lynne Madden is production manager.

The Bulletin aims to provide its readers with population health data and information to motivate effective public health action. Articles, news and comments should be 1,000 words or less in length and include a summary of the key points to be made in the first paragraph. References should be set out using the Vancouver style, the full text of which can be found in British Medical Journal 1988; 296:401-5.

Please submit items in hard copy and on diskette, preferably using WordPerfect, to the editor, NSW Public Health Bulletin, Locked Mail Bag 961, North Sydney 2059. Facsimile (02) 93919029.

Please contact your local Public Health Unit to obtain copies of the NSW Public Health Bulletin. The Bulletin can be accessed via the Internet from the NSW Health Department's World Wide Website, at

http://www.health.nsw.gov.au/public-health/phb/phb.html

Back issues can be obtained from the Better Health Centre, Locked Mail Bag 961, North Sydney 2059.

Telephone: (02) 9954 1193, Facsimile (02) 99555196. 